\title{
Coupling Continuum and Pore-Network Models for Polymer-Electrolyte Fuel Cells
}

\author{
Iryna V. Zenyuk ${ }^{1}$, Ezequiel Medici ${ }^{2}$, Jeffrey Allen ${ }^{2}$, and Adam Z. Weber ${ }^{1 *}$ \\ ${ }^{1}$ Energy Storage and Distributed Resources Division, \\ Lawrence Berkeley National Laboratory, Berkeley, CA 94720, USA \\ e-mail: ivzenyuk@lbl.gov, azweber@lbl.gov \\ *Corresponding author: 1 Cyclotron Road MS 70-108B Berkeley CA 94720 \\ ${ }^{2}$ Department of Mechanical Engineering-Engineering Mechanics, \\ Michigan Technological University, Houghton, MI 49931, USA \\ e-mail: efmedici@mtu.edu, jstallen@mtu.edu
}

Three novel iterative methodologies for coupling continuum and pore-network models (PNM) applied to polymer-electrolyte fuel cells (PEFCs) are presented. The modeling framework developed in this work merges the advantages of a continuum model, such as computational time, ease of implementation, and complicated physics, with those of relatively novel PNMs, such as discrete information on water-front location and distribution. The outputs generated by the PNM are fed into the continuum model to compute electrochemical reaction rates and associated heat and mass fluxes. Out of three presented coupling methodologies, the most effective coupling is identified to be where locallyresolved effective diffusivity, thermal conductivity, and liquid permeability are computed with the PNM and fed into the continuum model and the fluxes from continuum model fed back into the PNM in an iterative scheme until solution convergence is reached. The described method is computationally efficient with stable convergence of less than five iterations. The proposed algorithms can be applied to multiple computational platforms and PEFC and related model architectures.

\section{Keywords}

Pore-network model; continuum model; polymer-electrolyte fuel cells; gas-diffusion layer; modeling; water management; two-phase 


\section{Introduction}

Polymer-electrolyte fuel cells (PEFCs) are promising electrochemical energyconversion devices due to their thermodynamic efficiency and high power density $[1,2]$. Effective water management is essential for the performance and stability of these zeroemission devices. At low temperatures, liquid water is produced in the cathode electrode and is removed into the gas flow channel through porous gas-diffusion layers (GDLs). Water accumulation is undesirable in these porous, hydrophobic-treated carbon layers due to blocking of the reactant transport pathways to the electrode surface by water clusters $[3,4]$. At higher temperatures, phase-change-induced flow occurs, where most of the water removal is through the vapor phase driven by thermal gradients $[5,6]$. In addition, operation at higher temperatures and/or lower humidities can result in membrane dehydration and increased ohmic losses. Thus, there is a need to optimize PEFC water and thermal management.

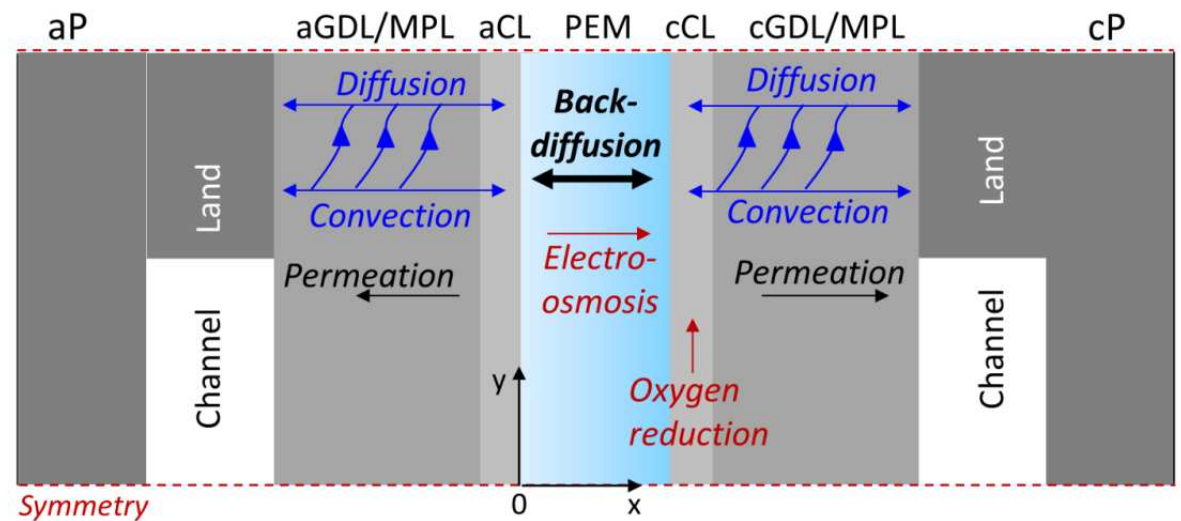

Figure 1. Two-dimensional model domains used for continuum model, where different transport pathways are shown for water transport in a PEFC.

The existence and transport of water in PEFCs is highly complex as shown in Figure

1. Figure 1 also shows the modeling domains that include membrane (PEM), cathode and anode plate (P), lands and channels (CHs), gas-diffusion layers (GDLs), and catalyst layers (CLs). Due to the inherent nonlinearities, mathematical modeling at the macroscopic, 
continuum scale has been increasingly used to explore PEFC transport phenomena [4]. These two-phase, continuum PEFC models use a volume-averaged approach to couple mass and energy transport and electrochemistry $[4,7,8]$. While continuum models allow for many of the complex PEFC phenomena to be accounted for, the microstructural information is simplified or coarse-grained. For example, water transport in the porous domains, such as the GDLs, is commonly described with Darcy's law, where the effective liquid permeability is adjusted depending on the liquid-water saturation, which is computed using experimental water-retention curves [9-11]. These curves provide volume-averaged saturation for a GDL at a particular liquid pressure. However, local spatial information is missing, which can introduce a significant error, as discussed recently [12-14]. Similarly, in continuum models, the reactant bulk diffusion coefficient is modified for a GDL's morphology (porosity) and liquid saturation to derive an effective tortuosity [15-17]. While the volume-averaged approach works well for bulk porous materials, it does not work for thin porous layers such as GDLs, especially since recent X-ray computed tomography studies have shown that water percolation through them is mainly due to capillary fingering [12, 13, 18-23]. Moreover, due to volume-averaging, continuum models lack predictive capabilities when morphological heterogeneities and associated liquid-water gradients are present. Finally, the coupling between local heat generation and thermal and water management is similarly spatially compromised in GDLs when solely continuum models are used, and similar challenges are present with the smaller pore sizes in the CL and the microporous layer (MPL) where even less is known about phase-change dynamics.

An alternative modeling approach to the volume-averaged one is to utilize a porenetwork model (PNM) that discretizes the porous domain in order to solve a reduced set of transport relationships [24-27]. Factors that affect transport at the pore level can be modeled effectively in a computationally efficient manner. These models can capture capillary 
fingering, stable displacement, and viscous fingering instabilities observed experimentally, as well as compute water transport through GDLs with inhomogeneous morphology and wettability [28-32]. In addition, PNMs can be used to investigate thermal transport and liquid-vapor phase change in porous substrates [27]. Various PNMs have been developed to study mass transport in PEFCs. They provide an effective tool for describing phenomenological mechanisms of heat and mass transport inside the porous layers, and, because the formulation is defined at the pore level, effective properties such as permeability, effective thermal conductivity, and effective vapor diffusivity are an outcome of the simulation rather than an input as in continuum models. However, due to accounting for the complex microstructure, PNMs typically require simplification of the governing physics (e.g., Fickian transport instead of Stefan-Maxwell gas transport in GDLs), which is especially troublesome in PEFC membrane-electrode assemblies; thus, PNMs are not typically suitable for simulating PEFC operation due to the computational expense.

Herein, we present a direct integration of PNM into a two-dimensional, two-phase continuum model to improve the composite model's thermal and mass-transport predictive capability. Previously, some studies have coupled a discrete water-path percolation model to a continuum model using a complex iterative algorithm $[33,34]$, however only one method was proposed to link the two models [35]. The goal of this work is to establish a robust iterative architecture for model coupling that can be effectively replicated depending on application. Three different PNM-continuum coupling methods based on iterative algorithms are discussed. Depending on geometry and optimization parameters, one of the methods tailored for a specific application can be selected. In the first method, the coupling is achieved through the CL/GDL interface boundary condition. In the second and third methods, the coupling occurs through the use of effective GDL properties derived from the PNM. The stability and accuracy of each method are discussed. The three coupling methods 
are straight-forward, well-defined and can be easily incorporated within different computational packages.

\section{Model description}

\subsection{Continuum model}

For the continuum modeling study, the two-dimensional, nonisothermal, crosssection sandwich model as previously developed by Balliet and Newman [36, 37] and modified by Zenyuk et al.[38] was adopted. The model is two-phase and accounts for water transport in liquid and vapor phases as shown in Figure 1. Model dimensions and phases present in each domain are given in Table 1.

The detailed model description is presented elsewhere [36, 37], here the general physics and model modifications are shown. The continuum model assumes thermal equilibrium between different phases and the conservation of energy is used to find the spatial temperature, $T$, distribution:

$$
\sum_{\alpha} \varepsilon_{\alpha} \rho_{\alpha} \hat{C}_{p, \alpha}\left(\frac{\partial T}{\partial t}+v_{\alpha} \cdot \nabla T\right)-k^{e f f} \nabla \cdot(\nabla T)=Q_{v}+Q_{j l e}+Q_{r x n}
$$

where $\varepsilon_{\alpha}$ is the volume fraction of phase $\alpha, \rho$ is the density, $\hat{C}_{p}$ is specific heat, $k^{\text {eff }}$ is effective thermal conductivity. On the right-side, the source terms account for phase change, $Q_{v}$, joule heating, $Q_{j l e}$ and heat of reaction, $Q_{r x n}$.

Conservation of mass and Darcy's law are used to describe liquid and gas transport in the porous GDL and CL domains, 


$$
\frac{\partial\left(\rho_{\alpha} \varepsilon_{\alpha}\right)}{\partial t}+\nabla \cdot{ }_{\alpha}^{\mathbf{n}}=S_{v}+S_{r x n}
$$

and

$$
{ }_{\alpha}^{\mathbf{n}}=-\frac{\rho_{\alpha} k_{\alpha}^{\text {eff }}}{\mu_{\alpha}} \nabla P_{\alpha}
$$

respectively, where $\mu_{\alpha}$ is viscosity of phase $\alpha$ and $k_{\alpha}^{e f f}$ is the effective permeability of phase $\alpha$. On the right-side, the source terms are for phase change, $s_{v}$, and electrochemical reaction, $S_{r x n}$.

Stefan-Maxwell equation is used to describe diffusion of gas species,

$$
\begin{aligned}
& \frac{\partial\left(\rho_{G} \omega_{i}\right)}{\partial t}+\nabla \cdot\left(-\rho_{G} \omega_{i} \sum_{j}^{n} \bar{D}_{i j}^{e f f}\left(\nabla x_{j}+\left(x_{j}-\omega_{j}\right) \nabla P_{G} / P_{G}\right)\right)+\ldots \\
& \ldots+\rho_{G} \omega_{i} \quad{ }_{G}=s_{v, w_{R}}+s_{r x n, w_{R}}
\end{aligned}
$$

where $x_{j}$ and $\omega_{j}$ are molar and mass fractions of species $j$, respectively, and the effective diffusion coefficient, $\bar{D}_{i j}^{\text {eff }}$, accounts for gas-species transport through porous and tortuous pathways [39],

$$
\bar{D}_{i j}^{e f f}=\frac{\varepsilon_{G}}{\tau_{G}} \frac{p \bar{D}_{i j}}{P_{G}}
$$

and the pressure-independent binary diffusion coefficients, $p \bar{D}_{i j}$, depend on mixture composition [39] because Eq. [4] is an inverted form of the Stefan-Maxwell equation.

Capillary pressure, which is defined as a difference between liquid and gas pressures, $P_{c}=P_{L}-P_{G}$, and liquid-water saturation in the porous media are related through waterretention curves. In the model, a cubic-spline interpolation function is used from a look-up table created from experimentally measured curves for the GDL using a liquid-water imbibition/withdrawal technique [9]. The CL water-retention curve is approximated with the available in-house measurements for thick CLs [40]. 
Conservation of charge is applied to the solid phase to describe electron transport,

$$
\nabla \cdot{ }_{1}=\nabla \cdot\left(-\sigma^{e f f} \nabla \Phi_{1}\right)=-i_{h}^{r n n}
$$

where $\sigma^{\text {eff }}$ is the effective electronic conductivity of the solid phase and $\Phi_{1}$ is the potential in the electronically conductive phase. The reaction current for the hydrogen oxidation reaction (HOR) at the anode side is given by a Butler-Volmer equation,

$$
\left.j_{H O R}^{r x n}=j_{H O R, 0}\left[\frac{p_{H_{2}}}{p_{r e f}} \exp \left(\frac{\alpha_{a} F}{R T} \eta_{H O R}\right)-\exp \left(-\frac{\alpha_{c} F}{R T} \eta_{H O R}\right)\right)\right]
$$

where $j_{\text {ноR }, 0}$ is the HOR exchange current density, $p_{H_{2}}$ is the partial pressure of hydrogen, $\eta_{\text {нол }}$ is reaction driving kinetic overpotential, and $\alpha_{a}$ and $\alpha_{c}$ are the anodic and cathodic symmetry coefficients, respectively. For the oxygen reduction reaction (ORR) at the cathode, a double-trap reaction kinetic model is adopted [41-44]. In this formulation, a reaction can proceed through two adsorption pathways with four elementary reactions. The two pathways - O-adsorption and $\mathrm{OH}$-adsorption, as well as four elementary reactions (with labels) are shown in the following schematic:

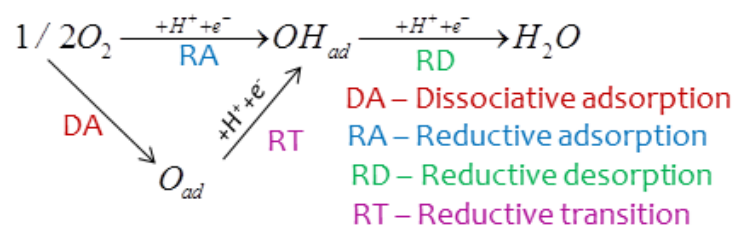

Using a steady-state approximation, the kinetic current can be expressed as a single reductive desorption (RD) step:

$$
j_{O R R}^{r x n}=j_{R D}=j^{*} \exp \left(-\Delta G_{R D}^{*} / k T\right) \theta_{O H}-j^{*} \exp \left(-\Delta G_{-R D}^{*} / k T\right)\left(1-\theta_{O}-\theta_{O H}\right)
$$

where, $j^{*}$ is a reference prefactor and $\Delta G_{R D}^{*}$ and $\Delta G_{-R D}^{*}$ are the potential-dependent activation free energies for the forward and backward reactions, respectively. The coverage of intermediate species, $\theta_{O}$ and $\theta_{O H}$, depend on the oxygen concentration and activation 
free energies. The isotherms for coverage and all other kinetic parameters are reported elsewhere [44].

The membrane model is adopted from Weber and Newman [45] and modified here to include water transport in liquid, $L$, and vapor, $V$, phases [46]. The model predicts transport of water and ions in the membrane and ionomer phase of the CLs. The conservation of ionic current, $i_{2}$, resolves proton transport in membrane and catalyst layers,

$$
\nabla \cdot i_{2}=i_{h}^{r x n}
$$

where ionic potential is described as

$$
(1-S)\left(\kappa_{V} \nabla \Phi_{2}+\frac{\kappa_{V} \xi_{V}}{F} \nabla \mu_{w}\right)+S\left(\kappa_{L} \nabla \Phi_{2}+\frac{\kappa_{L} \xi_{L}}{F} \nabla \mu_{w}\right)=-i_{2}
$$

where $\kappa$ is the ionic conductivity, $\xi$ is the electroosmotic coefficient, $S$ is the fraction of membrane in vapor- or liquid-equilibrated state.

Water transport in membrane and ionomer portion of the CLs is described by

$$
\frac{\partial\left(\rho_{L} \varepsilon_{0} \varepsilon_{M}\right)}{\partial t}+\nabla \cdot N_{w}=-R_{v, M}
$$

where $R_{v, M}$ is sorption rate and the flux of water is given by

$$
\begin{aligned}
& (1-S)\left(\frac{\kappa_{V} \xi_{V} M_{w}}{F} \nabla \Phi_{2}+M_{w}\left(\alpha_{V}+\frac{\kappa_{V} \xi_{V}^{2}}{F^{2}}\right) \nabla \mu_{w}\right)+\ldots \\
& \ldots+S\left(\frac{\kappa_{L} \xi_{L} M_{w}}{F} \nabla \Phi_{2}+M_{w}\left(\alpha_{L}+\frac{\kappa_{L} \xi_{L}^{2}}{F^{2}}\right) \nabla \mu_{w}\right)=-N_{w}
\end{aligned}
$$

Table 1 provides relevant transport parameters used in the continuum model. These were also the parameters for the first iteration of the continuum model, as during further iterations the GDL transport properties were updated with the parameters from the PNM simulations. The remaining model parameters are reported elsewhere [36, 37]. 
Table 1. Continuum model properties and parameters.

\begin{tabular}{|c|c|c|c|c|c|c|}
\hline & $\mathbf{P}$ & $\mathbf{C H}$ & GDL & CL & $\mathbf{M}$ & Units \\
\hline Thickness & 1000 & 500 & 210 & 0.5 & 25 & $\mu \mathrm{m}$ \\
\hline Length & 1000 & 1000 & 1000 & 1000 & 1000 & $\mu \mathrm{m}$ \\
\hline Phases present, $\alpha$ & $\mathrm{s}$ & G & $\mathrm{s}, \mathrm{G}, \mathrm{L}$ & $\mathrm{s}, \mathrm{G}, \mathrm{L}, \mathrm{M}$ & $\begin{array}{l}\text { s, G, L, } \\
\text { M }\end{array}$ & \\
\hline Porosity & 0 & 1 & 0.75 & 0.3 & & \\
\hline $\begin{array}{l}\text { Tortuosity exponent, } \\
\tau=S_{G}^{-\beta_{\tau}}\end{array}$ & & & 2 & 0.5 & & \\
\hline $\begin{array}{l}\text { Effective thermal } \\
\text { conductivity, } k_{T, e f f}\end{array}$ & 5 & & $0.3[47]$ & 0.29 & $\begin{array}{l}0.2[48, \\
49]\end{array}$ & $\mathrm{W} / \mathrm{mK}$ \\
\hline $\begin{array}{l}\text { Effective electric } \\
\text { conductivity, } \sigma_{s, e f f}\end{array}$ & 200 & & 15 & 43.4 & & $\mathrm{~S} / \mathrm{cm}$ \\
\hline Saturated permeability, $k_{\text {sat }}$ & & & $6.0 \times 10^{-8}$ & $8 \times 10^{-12}$ & & $\mathrm{~cm}^{2}$ \\
\hline $\begin{array}{l}\text { Rate constant for } \\
\text { evaporation/condensation, } \\
k_{v}\end{array}$ & & & $1 \times 10^{-3}$ & $1 \times 10^{-3}$ & & $\mathrm{gmol} / \mathrm{Jcm}^{3} \mathrm{~s}$ \\
\hline
\end{tabular}

\subsubsection{Continuum model boundary conditions}

At the outside of the bipolar plate, the temperature is set to the coolant temperature and assumed constant,

$$
T=T_{\text {cell }}
$$

For the Stefan-Maxwell equations, a reactant mass fraction and water vapor are specified, whereas the diluent mass fraction is determined from the mass balance. For liquid pressure at the $\mathrm{CH} / \mathrm{GDL}$ interface, a no-flux boundary condition is used if the liquid pressure is less than the gas pressure, else it is set equal to the gas pressure:

$$
\begin{aligned}
P_{L} & =P_{G} \text { for } P_{L} \geq P_{G} \\
-{ }_{w} & =0 \text { for } P_{L} \leq P_{G}
\end{aligned}
$$

The gas pressure at the $\mathrm{CH} / \mathrm{GDL}$ is set to the operating PEFC pressure. At the outside of the cathode bipolar plate, the electronic potential is set to the cell potential, whereas the anode bipolar plate is set to $0 \mathrm{~V}$ (reference). 
Below, in the section on model coupling, several of these boundary conditions will be revised depending on the coupling algorithm.

\subsection{Pore-network model}

The PNM used to simulate the mass transport inside the GDL is described in detail by Medici and Allen [27, 50]. Liquid and vapor water, heat, and reactant transport inside the GDL are simulated using a two-dimensional network model that consists of a regular lattice of cylindrical tubes of constant length. The cylindrical tubes represent the pore structure. The tubes are connected at the nodes in groups of four. All of the pore volume is assigned to the tubes; throats contain no volume. The random pore sizes or pore-size distribution, PSD, is obtained by fitting a Weibull probability distribution function to the porosimetry measurement of a given GDL. The fluid-flow behavior inside the network of pores is modeled as a modified Poiseuille flow to include two-phase flow and capillary-pressure effects. In a partially saturated pore, when the pressure between both ends ' $\mathrm{i}$ ' and ' $\mathrm{j}$ ' is larger than the capillary pressure, $P_{i j}>P_{i j}^{C}$, the volumetric flow rate is defined as

$$
q_{i j}=\frac{\pi r_{i j}^{4}}{8 \mu_{i j}^{2}}\left(\Delta P_{i j}-P_{i j}^{C}\right)
$$

otherwise $q_{i j}=0$. The effective viscosity within the pore, $\mu_{i j}^{e}$, is a function of the fluid position inside the pore, $x_{i j}$, and proportional to the amount of non-wetting (injected) and wetting (displaced) fluid viscosities. When the pore is filled with only one fluid, $\mu_{i j}^{e}$ is equal the viscosity of that fluid. The capillary pressure, $P_{i j}^{C}$, is also modeled as a function of the fluid position within each pore. The capillary pressure at the entrance of the pore is calculated using the average radius of the pores intersecting at that node. As the meniscus moves toward the middle of the pore, the capillary pressure is calculated using the radius of 
that pore. At the opposite end of the pore, the capillary pressure is again calculated using the average radius of the intersecting pores. The capillary pressure varies smoothly between two nodes using a combination of trigonometric functions,

$$
P_{i j}^{C}=\gamma \cos \theta\left[\left(1-\frac{r_{i j}}{2 \bar{r}_{i}}-\frac{r_{i j}}{2 \bar{r}_{j}}\right) \frac{1-\cos \left(2 \pi x_{i j} / l\right)}{r_{i j}}+\frac{1+\cos \left(2 \pi x_{i j} / l\right)}{\bar{r}_{i}}+\frac{1-\cos \left(2 \pi x_{i j} / l\right)}{\bar{r}_{j}}\right]
$$

The capillary pressure is zero when the pore is filled with only one fluid. Assuming incompressible flow, conservation of mass can be rewritten as a flow balance at each node for every time step in the simulation. The sum of the four flowrates of the four pores concurring at each node must be zero,

$$
\sum_{j=1}^{4} \frac{r_{i j}^{4}}{\mu_{i j}^{e}}\left(\Delta P_{i j}-P_{i j}^{C}\right)=0
$$

Heat transport includes heat conduction between nodes, latent heat due to phase change, and a lumped heat capacity. The temperature distribution along the GDL is solved by applying energy conservation around node 'i',

$$
\left(v \rho c_{p}\right)_{i} \frac{d T_{i}}{d t}=-\sum_{j=1}^{4} \frac{T_{i}-T_{j}}{R_{i j}}-\sum_{j=1}^{4}\left(\dot{m}^{e v} \Delta h^{e v}\right)_{i j}
$$

The total heat capacity around each node is the sum of the heat capacity of the carbon fibers, liquid water, water vapor, and reactants (air at the cathode side, hydrogen at the anode side). However, the heat capacities of the gases (vapor-reactant mixture) are negligible when compared to the liquid or solid heat capacities; therefore, the condensed phases are dominant when computing heat capacities and thermal conductivities.

Vapor and reactant (oxygen in the cathode side, hydrogen in the anode side) transport are modeled as one-dimensional diffusive transport between both ends of the pore. Using Fick's law of diffusion, the concentration gradient between the ends of the pore for vapor and reactant can be described as 


$$
v_{i} \frac{d c_{i}^{v}}{d t}=\pi r_{i j}^{2} D_{v} \frac{c_{i}^{v}-c_{j}^{v}}{l}
$$

and

$$
v_{i} \frac{d c_{i}^{R}}{d t}=\pi r_{i j}^{2} D_{R} \frac{c_{i}^{R}-c_{j}^{R}}{l}
$$

respectively, where $\boldsymbol{D}_{\boldsymbol{v}}$ is the binary vapor-air diffusivity for cathode side or vapor-hydrogen diffusivity for the anode side and $D_{R}$ is the composite oxygen-air-vapor diffusivity for cathode side or the hydrogen-vapor diffusivity for the anode side.

\subsubsection{Pore-network-model initial and boundary conditions}

To solve the 2-D PNM described by Eq. [18-21], initial and boundary conditions are required. Along symmetry axes, zero flux for pressure, temperature, and concentration equations are set. A Neumann boundary condition is set on the CL side with a specified liquid-water production, generated heat, and reactant-consumption flux. Channel/land boundary conditions are treated differently depending on the transport equation to be solved. The channel/land temperature boundary condition is set as a constant value, while the channel/pressure boundary condition is set equal to the gas-channel pressure. The channel vapor and reactant concentration boundary conditions are set based on the given relative humidity while the land concentration boundary conditions are set to zero flux. Initial conditions are set as uniform pressure, temperature, and concentrations throughout the GDL and equal to those in the gas channel. Simulations are run until a steady-state solution is reached in all four transport equations. The final steady-state solution is exported to the continuum model. 


\section{Coupling methods}

Three different methods are attempted to couple the continuum and PN models. These methods are based on iterative algorithms, where selected variables or parameters are passed between the continuum and PN models until convergence is reached. The three coupling methods and model outputs for every coupling scheme are shown in Figure 2a-c. The details of model coupling and advantages/disadvantages for a particular method are listed in Table 2.

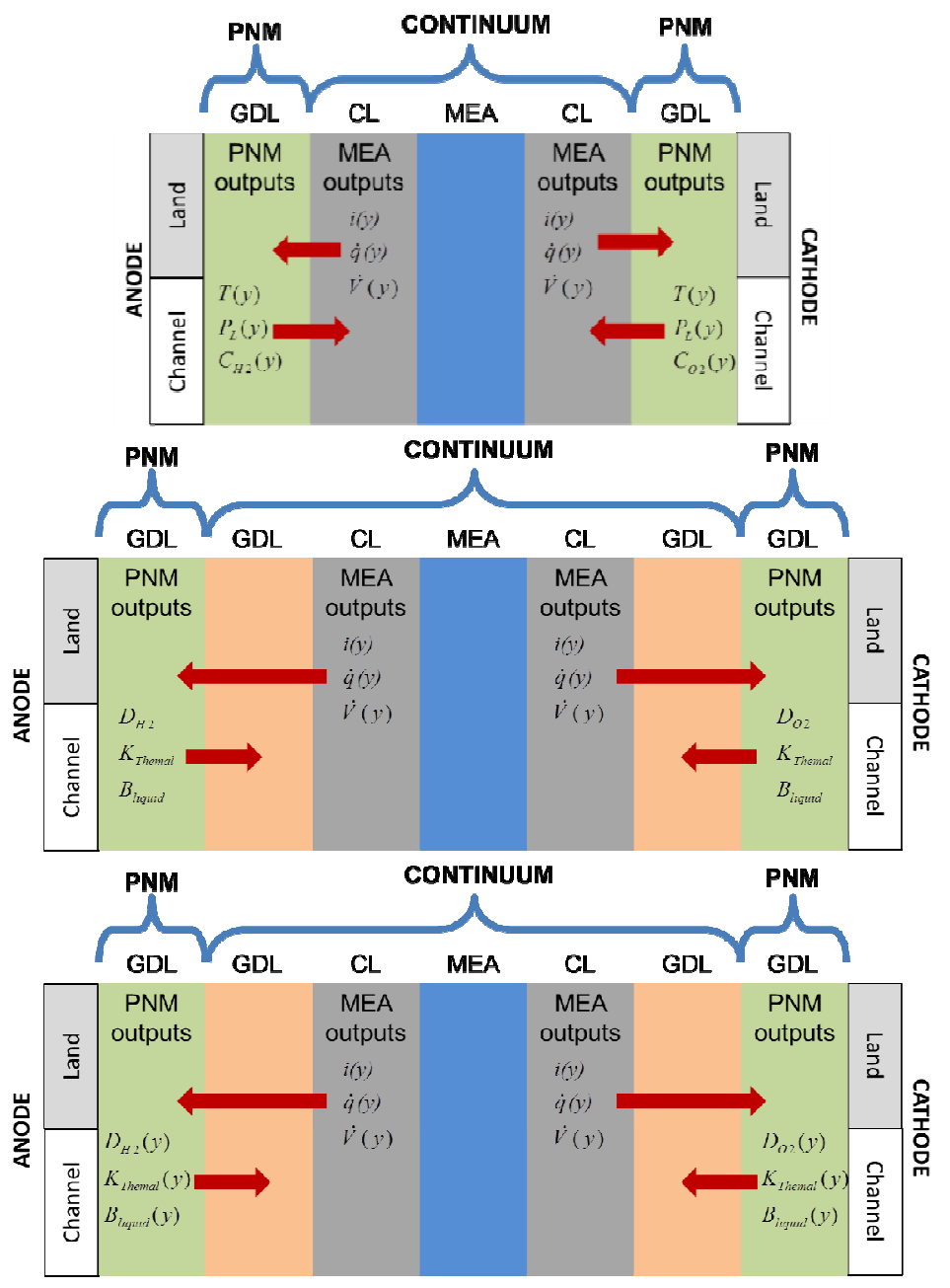

Figure 2. Schematic of Continuum-PNM coupling methods where output parameters are shown for a) method 1, b) method 2 and c) method 3. The domain dimensions are reported in Table 1. 
Table 2. A comparison table for three methods of model coupling, where coupling parameters are outlined and advantages/disadvantages discussed.

\begin{tabular}{|c|c|c|c|}
\hline & Method 1 & Method 2 & Method 3 \\
\hline Means of coupling & CL./GDL boundary & $\begin{array}{c}\text { Effective transport } \\
\text { parameters }\end{array}$ & $\begin{array}{c}\text { Spatially-varied } \\
\text { effective transport } \\
\text { parameters }\end{array}$ \\
\hline Continuum output & $\begin{array}{l}\text { Current, } i(y) \text {, heat } \\
\text { flux, } q(y) \text { and water } \\
\text { flux, } R(y)\end{array}$ & $\begin{array}{l}\text { Current, } i(y) \text {, heat } \\
\text { flux, } q(y) \text { and water } \\
\text { flux, } R(y)\end{array}$ & $\begin{array}{l}\text { Current, } i(y) \text {, heat } \\
\text { flux, } q(y) \text { and water } \\
\text { flux, } R(y)\end{array}$ \\
\hline PNM output & $\begin{array}{l}\text { Temperature, } T(y), \\
\text { liquid and gas } \\
\text { pressures, } P_{L}(y) \text { and } \\
P_{G}(y), \text { molar fraction } \\
\text { of oxygen, } c_{O 2}(y)\end{array}$ & $\begin{array}{l}\text { Thermal conductivity, } \\
\qquad K_{\text {eff }} \text {, liquid } \\
\text { permeability, } B_{l}, \\
\text { oxygen effective } \\
\text { diffusivity, } D_{e f f}\end{array}$ & $\begin{array}{l}\text { Thermal conductivity, } \\
\qquad K_{\text {eff }}(y) \text {, liquid } \\
\text { permeability, } B_{l}(y), \\
\text { oxygen effective } \\
\text { diffusivity, } D_{\text {eff }}(y)\end{array}$ \\
\hline Advantages & $\begin{array}{l}\text { Consistency, as PNM } \\
\text { resolves physics } \\
\text { beyond MEA; } \\
\text { Boundary condition } \\
\text { coupling }\end{array}$ & $\begin{array}{l}\text { Ease of } \\
\text { implementation; } \\
\text { Computationally } \\
\text { inexpensive }\end{array}$ & $\begin{array}{c}\text { Captures spatial } \\
\text { variations; } \\
\text { Resolves land/channel } \\
\text { effects }\end{array}$ \\
\hline Disadvantages & $\begin{array}{l}\text { Convergence due to } \\
\text { CL having high ORR } \\
\text { fluxes; } \\
\text { PNM does not have all } \\
\text { the physics Continuum } \\
\text { does }\end{array}$ & $\begin{array}{c}\text { Effective parameters } \\
\text { do not capture spatial } \\
\text { anisotropy; } \\
\text { Land/channel effects } \\
\text { can be under/over } \\
\text { approximated }\end{array}$ & $\begin{array}{l}\text { Continuum and PNM } \\
\text { have different length- } \\
\text { scales, challenging to } \\
\text { find correct } \\
\text { representative area. }\end{array}$ \\
\hline
\end{tabular}

In method 1 , the coupling is achieved through the CL/GDL interfacial boundary condition as Figure 2a shows. The continuum PEFC model predicts the heat and mass fluxes, which is used as a source term at the CL/GDL boundary in the PNM. In return, the PNM predicts the temperature, liquid pressure, and molar concentration of oxygen (cathode side) and hydrogen (anode side) at the CL/GDL interface, which are used as inputs to the continuum model. For the continuum model, the molar concentrations of the other species are computed with the mass balances and temperature distribution (for vapor pressure). In this method, all the inputs and outputs are spatially-resolved in the CL-GDL(" $y$ ") direction. As listed in Table 2, the advantage of method 1 is that the coupling is self-consistent. The continuum model solves for physics in the membrane and CLs, whereas the PNM produces a 
solution for all the domains and physics beyond those layers. Thus, the continuum model needs boundary conditions at CL/GDL interface that are fed from the PNM. This method has the highest potential to be adopted for the direct schemes, where both models run simultaneous within a single commercial or open-source computational package. Before its successful implementation, several challenges need to be resolved. The CL/GDL interface fluxes and boundary conditions are sensitive to the current-density distribution, which depends on the oxygen concentration. Severe fluctuations in oxygen concentration produce model convergence problems due to substantial changes in the current distribution from one iteration to the next. Another implementation challenge is the selection of a proper representative volume for the GDL domains to preserve length-scales [51]. The minimum spatial resolution along the CL/GDL interface chosen is the pore length used in the PNM.

In method 2, the models' coupling is done through the use of effective GDL properties as shown by Figure $2 \mathrm{~b}$. While again, the continuum model provides the input fluxes, the PNM returns the overall effective properties under the simulated conditions. Effective thermal conductivity, liquid permeability, and oxygen diffusivity are the transport properties representative of the temperature, liquid pressure, and oxygen concentration distributions along the cathode GDL, respectively. Implementing this method is a straightforward procedure and it is computational inexpensive. However, it has several disadvantages including that the effective properties are area-averaged along the GDL and do not resolve spatial anisotropy, such as land/channel effects, local defects, etc. as pointed out in Table 2.

Method 3 is a hybrid method between the first two methods, where the PNM returns the effective properties, now discretized in $y$-direction along the CL/GDL interface as shown in Figure 2c. Anisotropy and land/channel effects are captured through the spatially-resolved 
effective transport parameters. One of the challenges of this method is similar to that of method 1, which is selecting the correct representative CL/GDL interface discretization.

Another challenge to overcome for implementation of the continuum and PNM coupling was the selection of a computational platform. In this particular project, the continuum model (Comsol 5.0 multiphysics software with Matlab LiveLink) and PNM (Fortran) were coupled using Matlab, which was also used to perform all the postprocessing analysis and storage of simulation results. Although implemented in different computational packages, the algorithms described in this article should not represent a significant programing challenge when developed using a single programing language/platform [52]. Figure 3 shows the flowchart for the coupling algorithms. All three methods have different integrated interfaces because inputs and outputs to the models vary depending on method used. This robust integration scheme allows independent modification of the continuum and PN models without affecting the common interface. The inputs to both models are the PEFC's operational conditions, domain geometry, and material properties. Fluxes at the CL/GDL interface from the continuum model are fed into the PNM. By default, the PNM computes the local spatial distributions of dependent variables (e.g. temperature, liquid pressure, concentrations, and water content) and the associated effective transport properties. These stored variables (discussed in Coupled Model Methodology section) are averaged along the CL/GDL and are compared to the previous solution to check for convergence. If the convergence criterion is not met, then the output of the PNM is fed back to the continuum model and reiterated. 


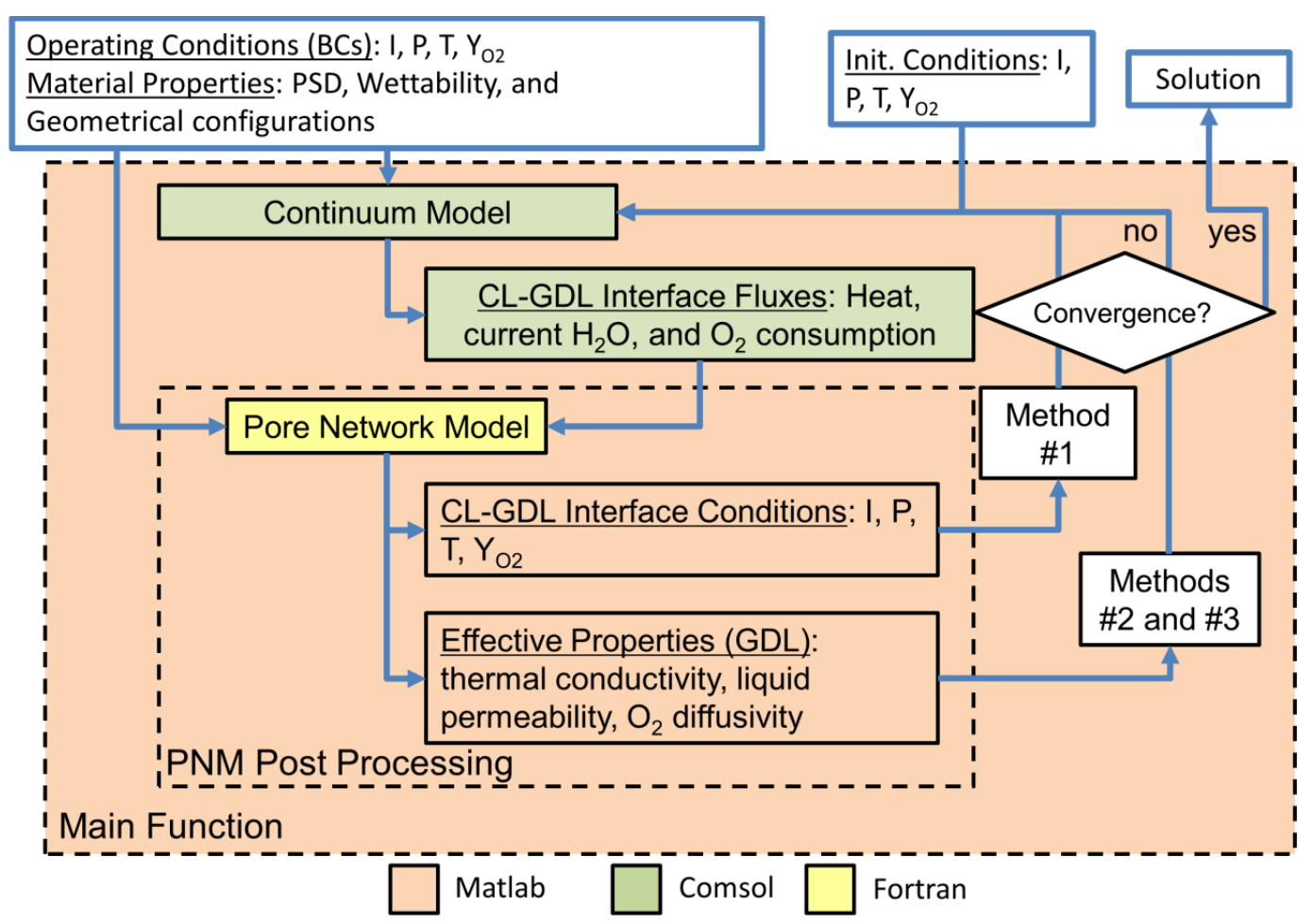

Figure 3. Coupling algorithm between the Continuum (green) and PNM (yellow) where the Matlab (orange) interface is used as a main function.

\section{Materials and Model Parameters}

\subsection{Membrane and Catalyst-Layers Material Properties}

The double-trap kinetics model couples the electrochemical surface area and $\mathrm{Pt}$ loading into an exchange current prefactor, therefore these parameters did not have to be specified. For baseline simulations, a $25 \mu \mathrm{m}$ thick membrane with equivalent weight of 850 $\mathrm{g} / \mathrm{mol}$ developed by $3 \mathrm{M}$ is used. The fit for a vapor-equilibrated water content, $\lambda_{V}$, as a function of water activity, $a_{0}$, was created using in-house experimental data:

$$
\lambda_{V}=\min \left(0.38+14.84 a_{0}-35.69 a_{0}^{2}+39.47 a_{0}^{3}, 17\right)
$$

Percolation theory was used to fit membrane conductivity and diffusion coefficient from experimental data [45]: 


$$
\begin{gathered}
\kappa_{V}=0.27(f-0.057)^{1.15} \exp \left[\frac{14,468}{R}\left(\frac{1}{T_{t}}-\frac{1}{T}\right)\right] \mathcal{E}_{M}^{1.5} \\
\kappa_{L}=0.5(0.39)^{1.5} \exp \left[\frac{15,000}{R}\left(\frac{1}{T_{t}}-\frac{1}{T}\right)\right] \mathcal{E}_{M}^{1.5} \\
D_{\mu_{0}}=2.26 e-5 \varepsilon_{0} \exp \left[\frac{20,000}{R}\left(\frac{1}{T_{t}}-\frac{1}{T}\right)\right]
\end{gathered}
$$

where the volume fraction of water in the membrane is

$$
f=\frac{\lambda \bar{V}_{0}}{\bar{V}_{m}+\lambda \bar{V}_{0}}
$$

where $\overline{V_{m}}$ and $\overline{V_{0}}$ being the partial molar volumes of dry membrane and water, respectively.

The volume-fraction of the ionomer, $\varepsilon_{M}$, in the CL is assumed to be 0.12 .

\subsection{GDL Material Properties}

The GDL pore structure was generated using a combination of Weibull distribution function to fit the experimentally measured porosimetry data (Porous Materials Inc.) of an MRC U105 GDL. The porosimetry data was scaled by differential volume over the pore volume $d V / r^{3}$. Weibull distributions are defined by the scale and shape factors. The three distributions have the following defining factor:

$$
\begin{aligned}
& \left.\begin{array}{c}
\text { Scale Factor }=1.2 \\
\text { Shape Factor }=4
\end{array}\right\} \text { for } 0<r<2.4 \mu m \\
& \left.\begin{array}{c}
\text { Scale Factor }=2 \\
\text { Shape Factor }=5.5
\end{array}\right\} \text { for } 2.4<r<3.7 \mu m \\
& \left.\begin{array}{c}
\text { Scale Factor }=4 \\
\text { Shape Factor }=11
\end{array}\right\} \text { for } 3.7<r<20 \mu \mathrm{m}
\end{aligned}
$$

Figure 4 shows the pore realization as defined by the Weibull distributions and the porosimetry measurement scaled by $d V / r^{3}$. The same pore realization was used to model 
the anode and cathode GDLs. The contact angle for this GDL is 135 degrees and the thickness is $210 \mu \mathrm{m}$. Land and channel lengths were set as $0.5 \mathrm{~mm}$ each.

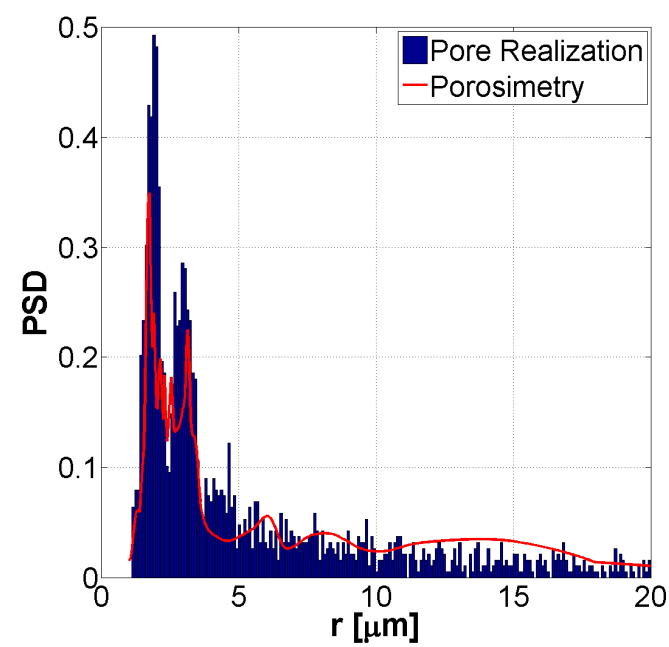

Figure 4. Porosimetry measurement and pore realization for MRC U105 GDL used in for the PNM anode and cathode GDLs.

\subsection{Operating Conditions}

Operating conditions were selected to test the convergence of the three methods. These conditions, $100 \%$ relative humidity, $40^{\circ} \mathrm{C}$, and $0.4 \mathrm{~V}$ were chosen to observe liquidwater generation and transport. The operating pressure was $150 \mathrm{kPa}$ for both anode and cathode.

\section{Results and Discussion}

In this section, we first explore the convergence of the three models and present percentage error for each method after ten iterations. Next, the model current densities after ten iterations from each methodology are shown and discussed. Finally, sample results for temperature and oxygen concentration, liquid pressure, and liquid-water distribution are examined. 


\subsection{Coupling Methodology Selection}

After each iteration step, as shown in Figure 3, a convergence criterion is checked to assess whether the final solution has been reached. The model tracks multiple output variables and several variables representative of the modeling physics are chosen to evaluate the convergence criteria. To be consistent with the models formulations, the output variables from each model were tracked. For the continuum model, these were: current, $i(y)$, heat flux, $q(y)$, and water flux, $R(y)$. For the PNM, the variables that determined convergence were: temperature, oxygen concentration, and liquid pressure. The error was defined as

$$
\text { Error }=\left\langle\frac{\left|\Psi_{i+1}-\Psi_{i}\right|}{\Psi_{i}}\right\rangle \times 100
$$

where, ' $\Psi$ ' represents a variable, ' $i$ ' is the iteration number, \langle\rangle is spatial average of the variable. To show an example of convergence history the number of iterations was set arbitrarily to 10 .

Figure 5a-c shows the error for ten iterations for the three continuum model outputs: current, water, and heat fluxes. The lines show error on the cathode side, however, a similar convergence history was observed for the anode side. For method 1, as shown in Figure 5a, the current fluctuates between 1 and $22 \%$ with no indication of error amplitude reduction after 10 iterations. Water and heat fluxes on the cathode side mimic this fluctuation but with higher error-amplitude magnitudes because these fluxes are proportional to current density. The sensitivity of method 1 is evident as no clear convergence is achieved even after ten iterations. This is due to the sensitive oxygen reduction reaction at the CL/GDL interface, where the current is strongly coupled to the oxygen concentration that is fed directly by the PNM. A potential solution would be to use smoothing or dampening functions for parameters input into the continuum model to aid in convergence. 

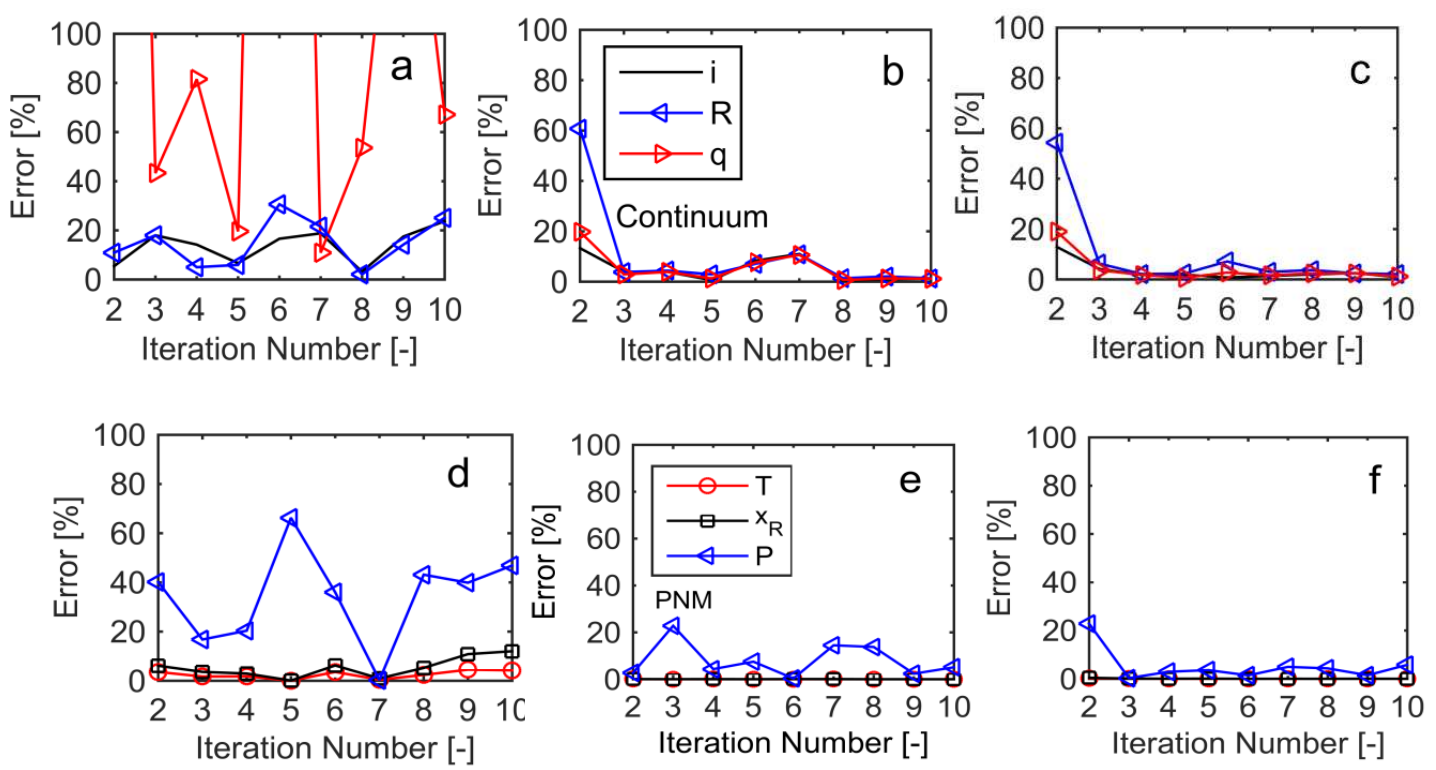

Figure 5. Plot of averaged error as a function of iteration number for a) method 1, b) method 2 and c) method 3 in the continuum model, where the tracked variables are the model outputs: current, total heat, and water flux at the cathode side. Plot of averaged error as a function of iteration number for d) method 1, e) method 2, and f) method 3 from the PNM, where the tracked variables are: temperature, reactant mole fraction, and liquid pressure.

Method 2 showed an error of less than $4 \%$ after iteration four, with some fluctuations at further iterations as shown in Figure 5b. All three fluxes show a similar error trend, indicating that fluxes due to current generation are the largest. A similar behavior was observed in the error calculations for method 3 as shown in Figure 5c. In method 3, the error remained below $5 \%$ for iterations 4 thru 10 . Comparing methods 2 and 3 , it is clear that spatial variation for effective parameters introduced in method 3 has not caused convergence problems, instead it contributed somewhat to model stability.

For the PNM convergence, the cathode temperature, reactant mole fraction (oxygen for cathode), and liquid pressure were tracked. The results for method 1 iterations, shown in Figure $5 \mathrm{~d}$, demonstrate error lower than $20 \%$ for the last five iterations and lower than $10 \%$ for the first five iterations for temperature and reactant molar fractions. The error due to liquid-pressure fluctuation, although with a decreasing tendency with the number of iterations, is $48 \%$ at iteration number 10 . These pressure fluctuations are due to the PNM 
predicting different water/gas interface front shape and location for each iteration due to the stochastic nature of the GDL pore structure. This large pressure variation causes fluctuations in current as shown by Figure 5a. Method 2 shows an error below 2\% for temperature and reactant concentration with a maximum $22 \%$ error for liquid pressure. Method 3 shows an error below $1 \%$ for temperature and reactant concentration with a decreasing trend for liquid-pressure error reaching $4 \%$ for the cathode side by the $10^{\text {th }}$ iteration as shown in Figure 5f. Although method 3 shows a higher liquid-pressure error during the first iteration, its overall error is lower than that for Method 2 for the remaining iterations.

\subsubsection{Computational Expense}

From the error plots shown in Figure 5, it appears that five iterations were sufficient for the continuum model to converge for methods 2 and 3. Method 1 needs an additional loop for smoothing input parameters to achieve higher stability. For the PNM, for temperature and reactant distributions, two to three iterations should be sufficient to keep the error below 5\%; however, due to the stochastic nature of the pressure fluctuations, reducing the error much further is not trivial.

Figure $6 a$ shows the computational time for each iteration for a coupled continuum and PNM simulation for each method. The continuum model is fast because of its volumeaveraged approach and the computational time for most iterations is below 100 seconds for all three methods; there are no significant differences between the time to complete an iteration for method 1,2 or 3 . For the PNM, it takes on average $787 \mathrm{~s}$ to complete a single iteration. This computational cost is due to the discrete nature of the PNM. Method 1 shows a higher computational time for iterations 1,4 , and 5 compared to the other methods. This is most likely due to large oscillations in the liquid pressure. Figure $6 \mathrm{~b}$ shows the cumulative 
time to run 1 to 10 iterations for the two models and three methods. On average, the slope of cumulative time for the PNM is eight times higher than that for the continuum model. Method 2 and 3 demonstrate similar computation times, whereas method 1 shows a higher computational time.
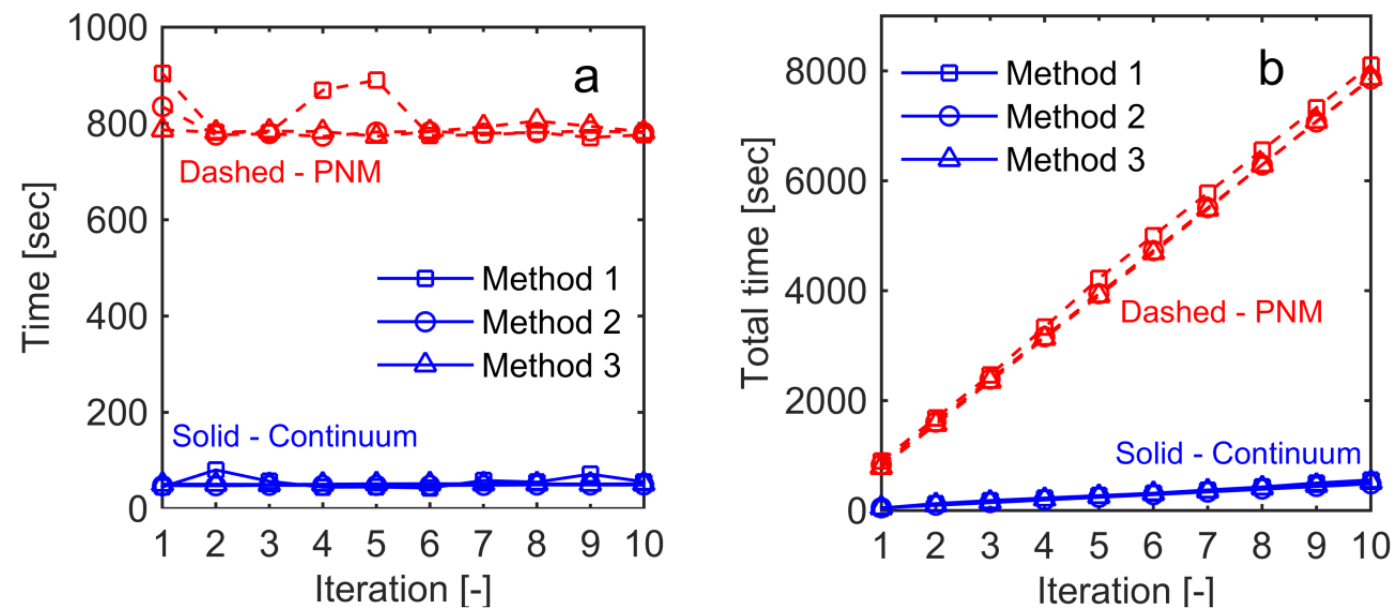

Figure 6. a) Time for each iteration for the continuum and PN models for three methods. b) Cumulative time for the iteration process for the two models and three methods.

\subsubsection{Coupled Model Accuracy}

In the previous section, we determined that the error due to the current fluctuation sets the trend for the other tracked fluxes. Here, the spatial distributions for current density at the CL/GDL interface for the three methods and ten iterations are shown in Figure 7. The results from Method 1 are plotted in Figure 7a. As mentioned, method 1 is unstable and requires extra modeling effort to reach convergence with a current density that varies between 1.4 and $2 \mathrm{~A} / \mathrm{cm}^{2}$. The spatial current density for methods 2 and 3 for ten iterations is shown by Figure $7 \mathrm{~b}$ and $\mathrm{c}$, respectively. Overall, the current trends for the two models are similar: current density is higher under the channel and lower under the land. Under the land, mass-transport limitations exist and hence a lower overall reaction rate and current density. For method 2, the current shows a smooth profile for all iterations. For Method 3, the current 
shows a spatial variability and, as will be shown in later sections, it follows the liquid-waterfront profile calculated by the PNM.
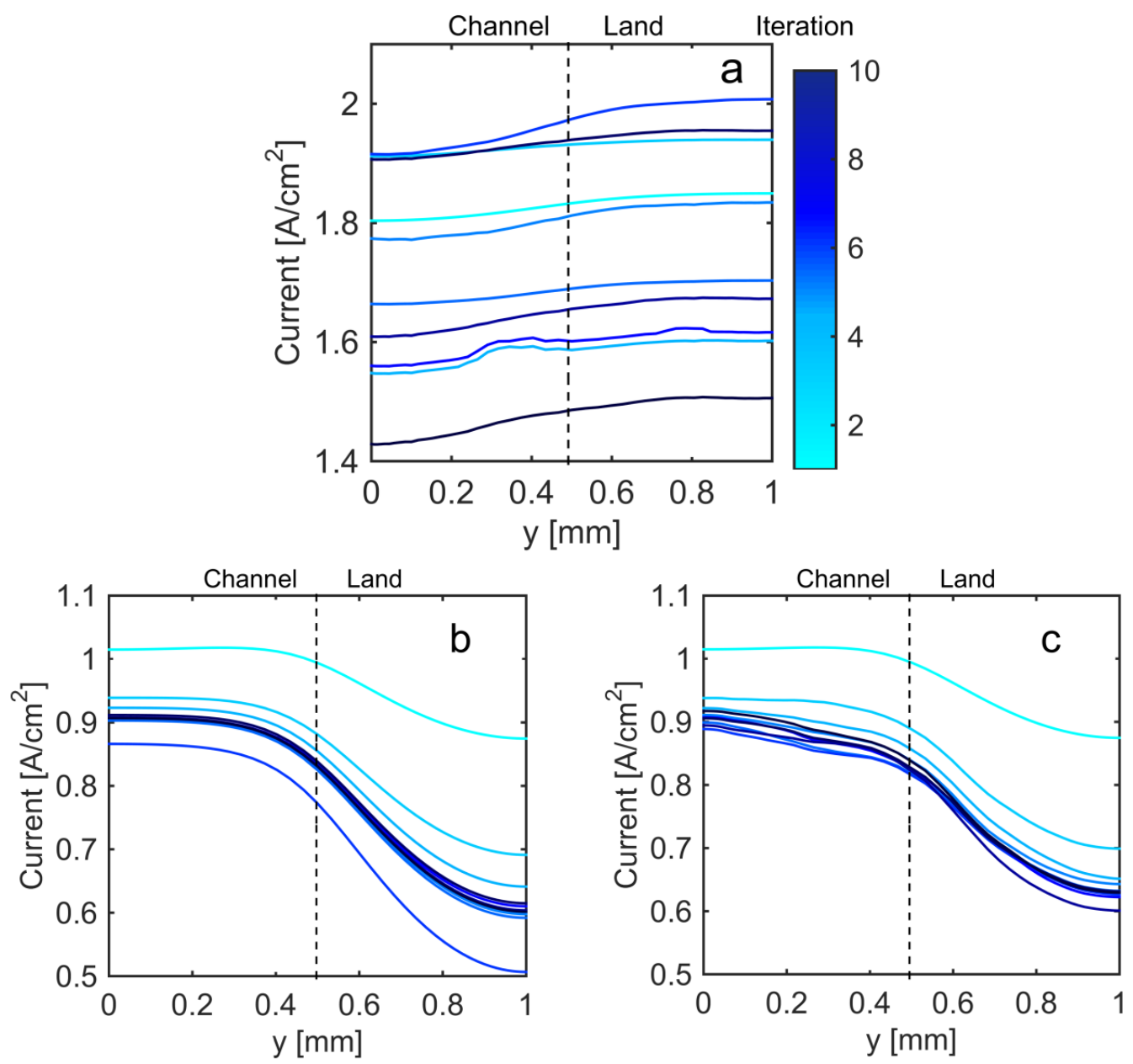

Figure 7. Spatial distributions of current density from the continuum model for a) method 1, b) method 2 and c) method 3. Locations of channel and land are shown.

For method 3, the spatial variations in effective properties are used to couple the PN and continuum models. Therefore, it is consistent to see nonuniform current profiles, unlike in method 2, where area-averaged effective properties are used and thus the spatial current density is not affected by local effective properties. The current for both methods peaks at $0.9 \mathrm{~A} / \mathrm{cm}^{2}$ under the channel and levels off to $0.6 \mathrm{~A} / \mathrm{cm}^{2}$ under the land. For the final iteration, the average current for method 2 is $0.78 \mathrm{~A} / \mathrm{cm}^{2}$ and for method 3 is $0.79 \mathrm{~A} / \mathrm{cm}^{2}$. 
The current predicted by the model is within the range of experimentally observed currents for the same operating conditions but higher cathode pressure as reported by Steinbach et al. [53]. In a follow-up study, we will report a detailed study of model calibration and experimental results prediction.

When comparing methods, convergence, computational time, accuracy, and problem physics have to be considered. Obviously, method 1 is a poor one to use. From the model convergence study shown by Figure 5, method 3 is more stable than method 2 and reaches convergence faster. The computational time is similar for methods 2 and 3 , as shown in Figure 6; however, because it takes more iterations for method 2 to converge, the overall computation time will be longer for method 2. From the current plots shown by Figure 7, both methods 2 and 3 show similar trends and area-averaged current density. Method 3 shows local fluctuations due to water front position and hence considers local flooding, whereas method 2 does not. From the above considerations, we conclude that method 3 has more advantages than method 2, and, in the next section, we concentrate on the results predicted by method 3 .

\subsection{Detailed Modeling Results}

For method 3, the current density, heat, and water fluxes along the cathode CL/GDL interface are the output parameters from the continuum model. The current-density distribution for ten iterations has already been shown by Figure $7 \mathrm{c}$. The distribution of heat and water fluxes at the cathode CL/GDL interface are shown in Figure 8a and b, respectively. The heat-flux profile follows that of current with about $3000 \mathrm{~W} / \mathrm{m}^{2}$ difference in heat generation between the channel and land locations. The heat flux starts showing fewer local oscillations after iteration 4 . The shape of the water flux profile is more uniform 
because water is redistributed with local evaporation and condensation processes. The spatial profile plotted here is the net liquid water flux that crosses the CL/GDL interface, which does not include water sorption into the membrane and back-diffusion through the anode side. Similar to the heat flux, the fluctuations in the water-flux magnitude after iteration 4 are minimal.
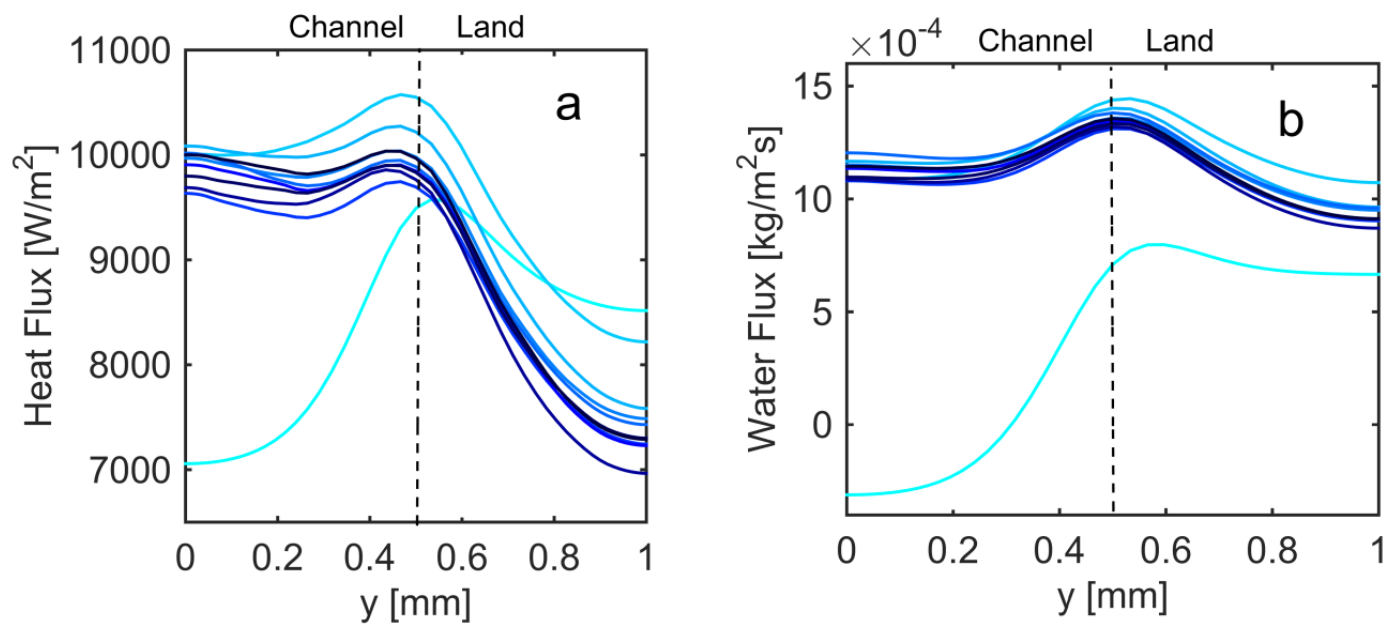

Figure 8. Output cathode coupling parameters from the continuum model where a) heat flux and b) water flux are plotted spatially at the CL/GDL interface for 10 iterations.

For method 3, the output results from the PNM are effective oxygen diffusion coefficient, thermal conductivity, and liquid permeability. The spatial distributions for these three effective properties for ten iterations are given in Figure 9. Although only the results from the cathode side are shown, similar trends were observed on the anode side. Oxygen diffusivity shows local fluctuations for all ten iterations. These fluctuations are due to the local water distribution predicted by the PNM, where high oxygen diffusivity corresponds to dry GDL and low oxygen diffusivity to local flooding. Convergence is reached after iteration 4, where a minimum in effective diffusivity of $2.6 \times 10^{-6} \mathrm{~m}^{2} / \mathrm{s}$ is witnessed at $0.3 \mathrm{~mm}$ under the channel. From the plots of current density and heat flux, it is apparent that these fluxes also show minima at the same location. The average diffusivity for the final iteration is $3.92 \times 10^{-6} \mathrm{~m}^{2} / \mathrm{s}$, with its maximum being $43 \%$ higher than the minimum. As discussed above, 
this significant variation in local property cannot be captured by method 2, where only averaged effective properties are passed. The order of magnitude $\left(10^{-6} \mathrm{~m}^{2} / \mathrm{s}\right)$ of effective diffusivity is consistent with published experimental values [15, 54-56].
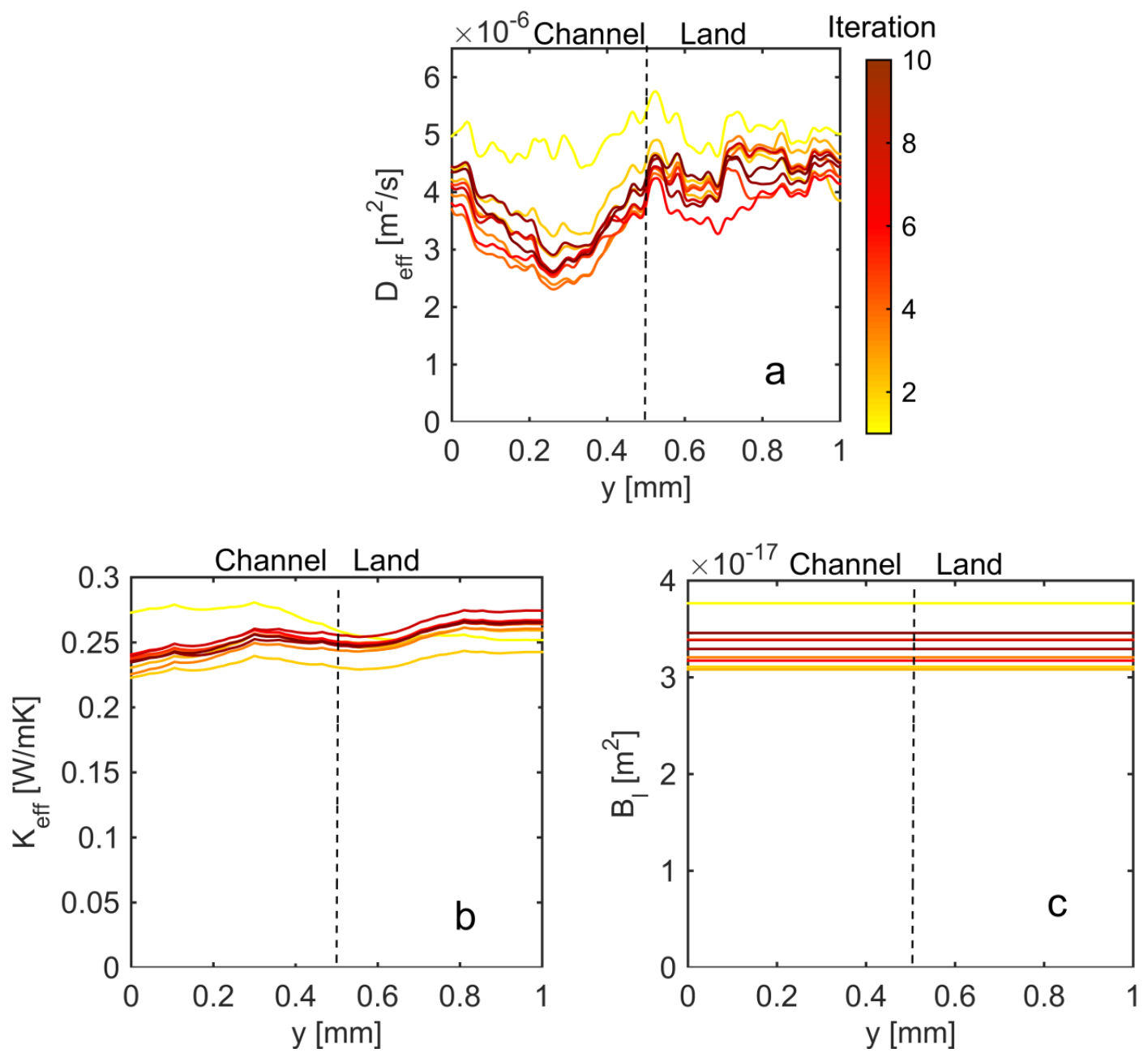

Figure 9. Output parameters from the PNM simulations for method 3, where spatial variations of cathode effective a) diffusivity, b) thermal conductivity and c) liquid permeability are plotted for ten iterations. The location of channel-land interface is shown.

Figure $9 \mathrm{~b}$ shows the spatial distribution for the effective thermal conductivity at the CL/GDL interface for ten iterations. After three iterations, the thermal-conductivity trend does not show significant variations in magnitude. For the final iteration, the effective thermal conductivity varies from $0.23 \mathrm{~W} / \mathrm{mK}$ under the channel to $0.26 \mathrm{~W} / \mathrm{mK}$ under the 
land. These values are consistent with the experimental measurements for MRC 105 GDL, where $0.26 \mathrm{~W} / \mathrm{mK}$ was reported for low GDL saturation values [47].

An inherent outcome of the PN simulations is the liquid-water pressure, which is effectively the pressure acting on the CL in the absence of an MPL. This pressure can be scaled through the concept of permeability for comparison with other published data, and as an input for the continuum model. Following the definition of Bear [57], the effective liquid water permeability is defined as

$$
B_{l}=Q \mu L / A P_{l}
$$

where $Q$ is the average injection flow rate, $\mu$ is the liquid water viscosity, $L$ is the GDL thickness, $A$ is the cross sectional area perpendicular to the direction of the water percolation, and $P_{l}$ is the pressure of the liquid-water phase. From the PNM, the liquid permeability was computed for the entire liquid front and plotted as an average value. Figure 9c shows the spatial distribution for the effective liquid permeability as predicted by the PNM. The computed permeability value fluctuates between 3.1 and $3.5 \times 10^{-17} \mathrm{~m}^{2}$ for iterations 2 thru 10. These values are in close agreement with to the value adopted by Alink and Gerteisen [35]. The average liquid pressure predicted by the PNM is 10 to $12 \mathrm{kPa}$, which is consistent with X-ray computed tomography experiments of water permeation through GDLs $[13,18]$. This effective liquid-water permeability, should not be mistaken with the effective gas permeability or the absolute permeability [54], for which commonly reported saturated permeability values from tests on GDLs is on the order of $10^{-12} \mathrm{~m}^{2}[58,59]$. The difference between the liquid-water and gas effective permeabilities is largely due to the capillary pressure, which is present only for the unsaturated liquid phase.

The power of the coupled model is to not just look at the overall fluxes, but also probe the local water distribution within the GDL. Figure 10 shows the liquid-water 
distributions predicted by the PNM for selected iterations. For iteration 1, the water front is uniformly distributed under the land and channel. From the current-density distribution shown by Figure 7c for iteration 1, the current is more uniform. For iteration 4, the water front is further advanced under the channel, which is once again consistent with the current density being higher there. For iterations 7 and 10, the water profile is very similar, indicating a converged solution. A large aggregation of water is observed at $0.3 \mathrm{~m}$, where from Figure 7c and Figure 8b, dips in current density and heat flux are observed. As in x-ray computed tomography experiments, the location of the water front is close to the location of water injection (CL) and the average liquid saturation is low [12, 13, 18-23]. Although evaporation and condensation are incorporated in both the continuum and PN models, no water is observed under the land (away from the CL). This is because at $40^{\circ} \mathrm{C}$ phase-changeinduced flow is negligible for the predicted temperature difference of $1.5^{\circ} \mathrm{C}$ between the land and channel [5].

As mentioned above, the effective gas diffusivity shown by Figure 9a is sensitive to water-front distribution. Local flooding impedes reactant delivery, thereby creating high transport-resistance pathways. The coupled model presented here can be used to predict local mass-transport limitations, especially for high current densities. Moreover, the algorithms described here are fit to describe the effects of the other local processes that cannot be properly accounted with volume-averaged approach. These include, but are not limited to, CL defects, membrane pinholes, and GDL anisotropy. 

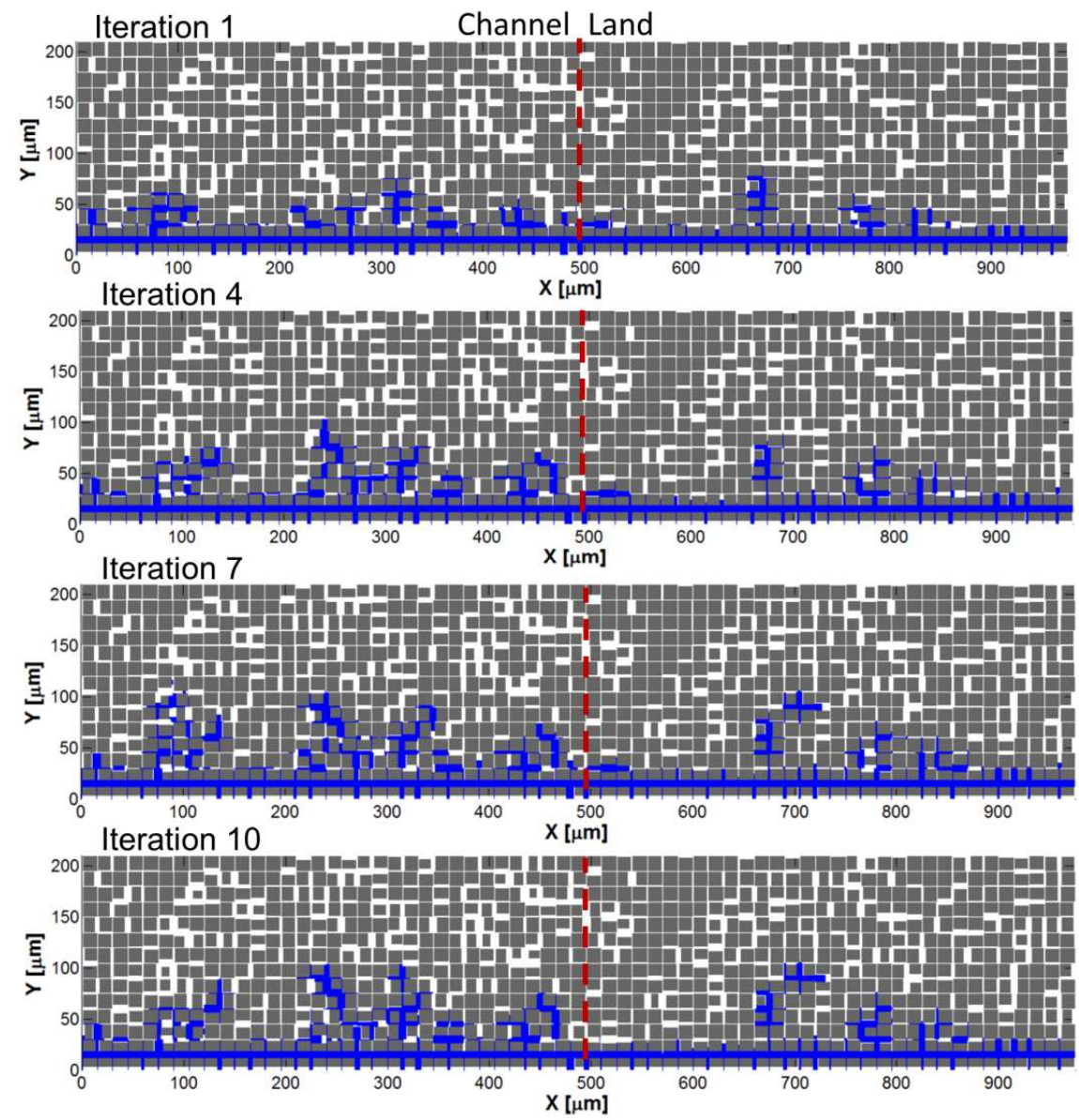

Figure 10. Liquid-water distributions predicted by the PNM for iterations 1, 4, 7 and 10 for $1 \mathrm{~mm}$ of GDL. The channel-land locations are marked.

\section{Conclusions}

In this paper, we presented and compared three novel iterative methodologies for coupling continuum and pore-network models (PNMs) in order to provide more accurate polymer-electrolyte fuel-cell performance predictions and understanding. PNMs predict local liquid-water distributions for a current density given by the continuum model, which can particularly be important for inhomogeneous GDLs, wherein local properties can have significant effect on the overall cell performance. The first coupling scheme is based on direct passing of boundary conditions at the CL/GDL interface between the continuum and PN models and is the most straight-forward and consistent method; however, it also 
demonstrated the highest convergence instability. The second and third methods are based on the PNM computing effective transport properties and the continuum model computing associated current density, heat, and water fluxes. The advantages of these two methods are that the two models can be running on different computational platforms and only several variables need to be passed between them. The third method proved to be the most stable and computationally inexpensive. It has advantages of resolving local inhomogeneity and land/channel effects, whereas the second method computes area-average effective properties that do not carry local information. Analysis of the results demonstrated local flooding, resulting in nonuniform current-density distributions, where the related variables and fluxes were greatly impacted by the GDL structure and land/channel architecture. Future work will focus on calibration of the coupled model against experimental polarization curves and x-ray computed tomography data, and simulations of different operating conditions to exploit the coupled model's predictive capabilities.

\section{Acknowledgements}

This work was supported by the Assistant Secretary for Energy Efficiency and Renewable Energy, Fuel Cell Technologies Office, of the U.S. Department of Energy under contract number DE-AC02-05CH11231 and DE-EE-0005667 in collaboration with 3M (who

provided cost share) as well as with funds from the John F. and Joan M. Calder Endowed Associate Professor in Mechanical Engineering and support from Department of Mechanical Engineering - Engineering Mechanics at Michigan Technological University. 


\section{Notation}

Abbreviations

\begin{tabular}{|l|l|}
\hline CH & channel \\
\hline CL & catalyst layer \\
\hline GDL & gas-diffusion layer \\
\hline MPL & micro-porous layer \\
\hline P & plate \\
\hline PEM & membrane \\
\hline PEFC & polymer-electrolyte fuel cell \\
\hline PNM & pore-network model \\
\hline
\end{tabular}

Roman

\begin{tabular}{|c|c|}
\hline$\hat{C}_{p}$ & molar heat capacity, $\mathrm{J} / \mathrm{molK}$ \\
\hline$B_{i}$ & liquid permeability, $\mathrm{cm}^{2}$ \\
\hline$D_{i j}$ & binary diffusion coefficient for species $\mathrm{i}$ in $\mathrm{j}, \mathrm{cm}^{2} / \mathrm{s}$ \\
\hline$D_{\mu_{0}}$ & membrane diffusion coefficient, $\mathrm{cm}^{2} / \mathrm{s}$ \\
\hline$E W$ & equivalent weight of membrane, g/equiv \\
\hline$F$ & Faraday's constant, $96487 \mathrm{C} / \mathrm{mol}$ \\
\hline$\Delta G$ & activation free energy, $\mathrm{J} / \mathrm{mol}$ \\
\hline$i, j$ & current density, $\mathrm{A} / \mathrm{cm}^{2}$ \\
\hline$k$ & permeability, $\mathrm{cm}^{2}$ \\
\hline$k_{k}$ & rate constant for phase-change path, $\mathrm{k}, \mathrm{gmol} / \mathrm{Jcm}^{3} \mathrm{~s}$ \\
\hline$k_{r, \alpha}$ & relative permeability of phase $\alpha$ \\
\hline$k^{\text {eff }}$ & Effective thermal conductivity of phase, W/cmK \\
\hline$l$ & length of domains, and length of the pore, $\mu \mathrm{m}$ \\
\hline$\dot{m}^{e v}$ & evaporation rate, $\mathrm{g} / \mathrm{m}^{3} \mathrm{~s}$ \\
\hline$M_{i}$ & molar mass of species i, $\mathrm{g} / \mathrm{mol}$ \\
\hline$P_{i}$ & partial pressure of species i, Pa \\
\hline$P_{\alpha}$ & total pressure of phase $\alpha, \mathrm{Pa}$ \\
\hline$q_{i j}$ & volumetric flow rate, $\mathrm{cm}^{3} / \mathrm{s}$ \\
\hline
\end{tabular}




\begin{tabular}{|l|l|}
\hline$r$ & radius of the pore, $\mathrm{cm}$ \\
\hline$R$ & ideal-gas constant, $\mathrm{J} / \mathrm{molK}$ and water flux, $\mathrm{mol} / \mathrm{m}^{2} \mathrm{~s}$ \\
\hline$R_{r}$ & rate of phase-change process $\mathrm{k}, \mathrm{g} / \mathrm{cm}^{3} \mathrm{~s}$ \\
\hline$R H$ & relative humidity, $\%$ \\
\hline$S_{\alpha}$ & saturation of phase $\alpha$ \\
\hline$S$ & mass flux, $\mathrm{g} / \mathrm{cm}^{3} \mathrm{~s}$ \\
\hline$t$ & time, $\mathrm{s}$ \\
\hline$T$ & temperature, $\mathrm{K}$ \\
\hline$Q$ & heat flux, $\mathrm{W} / \mathrm{cm}^{3} \mathrm{~s}$ \\
\hline$v_{\alpha}$ & velocity of phase $\alpha, \mathrm{cm} / \mathrm{s}$ \\
\hline$V$ & cell potential, $\mathrm{V}$ \\
\hline$V_{i}$ & (partial) molar volume of species i, $\mathrm{cm}^{3} / \mathrm{mol}^{3}$ \\
\hline
\end{tabular}

Greek

\begin{tabular}{|l|l|}
\hline$\alpha$ & phase or transfer coefficient \\
\hline$\beta$ & exponent in tortuosity and permeability relations \\
\hline$\gamma$ & surface energy, $\mathrm{N} / \mathrm{cm}$ \\
\hline$\delta$ & thickness, $\mu \mathrm{m}$ \\
\hline$\varepsilon_{\alpha}$ & volume fraction of phase $\alpha$ \\
\hline$\eta$ & overpotential, $\mathrm{V}$ \\
\hline$\kappa$ & ionic conductivity, S/cm \\
\hline$\lambda$ & membrane water content, $\mathrm{mol} \mathrm{H}_{2} \mathrm{O} / \mathrm{mol} \mathrm{SO}_{3}^{-}$ \\
\hline$\mu_{i}$ & $\begin{array}{l}\text { (electro)chemical potential of species } i, \mathrm{~J} / \mathrm{mol}^{-} \text {or dynamic } \\
\text { viscosity, Pas }\end{array}$ \\
\hline$\xi$ & electro-osmotic coefficient \\
\hline$\theta$ & coverage of intermediate species, and contact angle \\
\hline$\rho$ & density, g/cm \\
\hline$\sigma$ & electric conductivity, S/cm \\
\hline$\tau_{\alpha}$ & tortuosity of phase $\alpha$ \\
\hline$\Psi$ & variable \\
\hline$\Phi$ & potential, $\mathrm{V}$ \\
\hline$\omega_{i}$ & mass fraction of species i \\
\hline
\end{tabular}


Subscripts and superscripts

\begin{tabular}{|l|l|}
\hline 0 & reference value of membrane water \\
\hline 1 & electrically conductive phase \\
\hline 2 & ionically conductive phase \\
\hline a & anode \\
\hline c & cathode \\
\hline eff & $\begin{array}{l}\text { effective value corrected for porosity and } \\
\text { tortuosity }\end{array}$ \\
\hline$G$ & gas phase \\
\hline$i$ & species, and pore count \\
\hline$j$ & species, and pore count \\
\hline$L$ & liquid phase \\
\hline$M$ & membrane phase \\
\hline ref & reference value \\
\hline sat & saturated \\
\hline$V$ & water vapor \\
\hline
\end{tabular}




\section{References}

[1] S. Litster, G. McLean, Journal of Power Sources, 130 (2004) 61-76.

[2] M.K. Debe, Nature, 486 (2012) 43-51.

[3] A.Z. Weber, R.M. Darling, J. Newman, Journal of The Electrochemical Society, 151 (2004) A1715.

[4] A.Z. Weber, R.L. Borup, R.M. Darling, P.K. Das, T.J. Dursch, W. Gu, D. Harvey, A. Kusoglu, S. Litster,

M.M. Mench, R. Mukundan, J.P. Owejan, J.G. Pharoah, M. Secanell, I.V. Zenyuk, Journal of The Electrochemical Society, 161 (2014) F1254-F1299.

[5] A.Z. Weber, J. Newman, Journal of The Electrochemical Society, 153 (2006) A2205.

[6] S. Kim, M.M. Mench, Journal of Membrane Science, 328 (2009) 113-120.

[7] I.V. Zenyuk, R. Taspinar, A.R. Kalidindi, E.C. Kumbur, S. Litster, Journal of The Electrochemical Society, 161 (2014) F3091-F3103.

[8] M. Bhaiya, A. Putz, M. Secanell, Electrochimica Acta, 147 (2014) 294-309.

[9] J.T. Gostick, M.W. Fowler, M.A. Ioannidis, M.D. Pritzker, Y.M. Volfkovich, A. Sakars, Journal of Power Sources, 156 (2006) 375-387.

[10] A.Z. Weber, Journal of Power Sources, 195 (2010) 5292-5304.

[11] P.K. Das, A. Grippin, A. Kwong, A.Z. Weber, Journal of The Electrochemical Society, 159 (2012) B489B496.

[12] P.A. Garcia-Salaberri, Hwang G., Vera, M., Weber A.Z., Gostick J.T. , Journal of Heat and Mass Transfer, Submitted (2014).

[13] I.V. Zenyuk, D.Y. Parkinson, G. Hwang, A.Z. Weber, Electrochemistry Communications, 53 (2015) 2428.

[14] P.A. Garcia-Salaberri, Gostick J.T., Hwang G., Weber A.Z., Vera, M., Journal of Heat and Mass Transfer, Submitted (2015).

[15] G.S. Hwang, A.Z. Weber, Journal of The Electrochemical Society, 159 (2012) F683-F692.

[16] M.J. Martínez, S. Shimpalee, J.W. Van Zee, Journal of The Electrochemical Society, 156 (2009) B80-B85.

[17] J.H. Nam, M. Kaviany, International Journal of Heat and Mass Transfer, 46 (2003) 4595-4611.

[18] R. Flückiger, F. Marone, M. Stampanoni, A. Wokaun, F.N. Büchi, Electrochimica Acta, 56 (2011) 22542262.

[19] J.T. Gostick, H. Gunterman, B. Kienitz, J. Newman, A. MacDowell, A. Weber, ECS Transactions, 33 (2010) 1407-1412.

[20] F.N. Buechi, R. Flückiger, D. Tehlar, F. Marone, M. Stampanoni, ECS Transactions, 16 (2008) 587-592.

[21] J. Eller, T. Rosén, F. Marone, M. Stampanoni, A. Wokaun, F.N. Büchi, Journal of The Electrochemical Society, 158 (2011) B963.

[22] J. Lee, J. Hinebaugh, A. Bazylak, Journal of Power Sources, 227 (2013) 123-130.

[23] P. Deevanhxay, T. Sasabe, S. Tsushima, S. Hirai, Electrochemistry Communications, 34 (2013) 239-241.

[24] R. Lenormand, E. Touboul, C. Zarcone, Journal of Fluid Mechanics, 189 (1988) 165-187.

[25] A.G. Yiotis, A.K. Stubos, A.G. Boudouvis, Y.C. Yortsos, Advances in Water Resources, 24 (2001) 439460.

[26] V.K. Surasani, T. Metzger, E. Tsotsas, International Journal of Heat and Mass Transfer, 51 (2008) 25062518.

[27] E.F. Médici, J.S. Allen, International Journal of Heat and Mass Transfer, 65 (2013) 779-788.

[28] P.P. Mukherjee, Q. Kang, C.-Y. Wang, Energy \& Environmental Science, 4 (2011) 346-369.

[29] B. Markicevic, A. Bazylak, N. Djilali, Journal of Power Sources, 171 (2007) 706-717.

[30] A. Bazylak, V. Berejnov, B. Markicevic, D. Sinton, N. Djilali, Electrochimica Acta, 53 (2008) 7630-7637.

[31] J.T. Gostick, M.A. Ioannidis, M.W. Fowler, M.D. Pritzker, Journal of Power Sources, 173 (2007) 277290.

[32] O. Chapuis, M. Prat, M. Quintard, E. Chane-Kane, O. Guillot, N. Mayer, Journal of Power Sources, 178 (2008) 258-268.

[33] M.T. Balhoff, K.E. Thompson, M. Hjorts $\varnothing$, Computers \& Geosciences, 33 (2007) 393-410.

[34] J. Chu, B. Engquist, M. Prodanovic, R. Tsai, Multiscale Model. Simul., 10 (2012) 515-549.

[35] R. Alink, D. Gerteisen, International Journal of Hydrogen Energy, 39 (2014) 8457-8473.

[36] R. Balliet, in, 2010.

[37] R.J. Balliet, J. Newman, Journal of The Electrochemical Society, 158 (2011) B927.

[38] I.V. Zenyuk, Journal of Electrochemical Society, Submitted (2015).

[39] C.F. Curtiss, R.B. Bird, Ind Eng Chem Res, 38 (1999) 2515-2522.

[40] H.P.F. Gunterman, in, 2011.

[41] J.X. Wang, J. Zhang, R.R. Adzic, The Journal of Physical Chemistry A, 111 (2007) 12702-12710.

[42] J.X. Wang, F.A. Uribe, T.E. Springer, J. Zhang, R.R. Adzic, Faraday discussions, 140 (2009) 347-362. 
[43] R. Jinnouchi, K. Kodama, T. Hatanaka, Y. Morimoto, Physical Chemistry Chemical Physics, 13 (2011) 21070-21083.

[44] M. Moore, A. Putz, M. Secanell, Journal of The Electrochemical Society, 160 (2013) F670-F681.

[45] A.Z. Weber, J. Newman, Journal of The Electrochemical Society, 151 (2004) A311.

[46] A.Z. Weber, Journal of The Electrochemical Society, 155 (2008) B521.

[47] G. Xu, J.M. LaManna, J.T. Clement, M.M. Mench, Journal of Power Sources, 256 (2014) 212-219.

[48] M. Khandelwal, M.M. Mench, Journal of Power Sources, 161 (2006) 1106-1115.

[49] O.S. Burheim, H. Su, S. Pasupathi, J.G. Pharoah, B.G. Pollet, International Journal of Hydrogen Energy, 38 (2013) 8437-8447.

[50] E.F. Medici, J.S. Allen, Journal of The Electrochemical Society, 157 (2010) B1505-B1514.

[51] A.D. Santamaria, P.K. Das, J.C. MacDonald, A.Z. Weber, Journal of The Electrochemical Society, 161 (2014) F1184-F1193.

[52] J.G. Pharoah, J. Allen, R. Nishida, E. Medici, V. Konduru, K. Tajiri, Meeting Abstracts, MA2014-02 (2014) 1027.

[53] A.J. Steinbach, M.K. Debe, M.J. Pejsa, D.M. Peppin, A.T. Haug, M.J. Kurkowski, S.M. Maier-Hendricks, ECS Transactions, 41 (2011) 449-457.

[54] P. Mangal, L.M. Pant, N. Carrigy, M. Dumontier, V. Zingan, S. Mitra, M. Secanell, Electrochimica Acta, 167 (2015) 160-171.

[55] J.M. LaManna, S.G. Kandlikar, International Journal of Hydrogen Energy, 36 (2011) 5021-5029.

[56] N. Zamel, N.G.C. Astrath, X. Li, J. Shen, J. Zhou, F.B.G. Astrath, H. Wang, Z.-S. Liu, Chemical Engineering Science, 65 (2010) 931-937.

[57] J. Bear, Dynamics of fluids in porous media, 1988.

[58] B. Ramos-Alvarado, J.D. Sole, A. Hernandez-Guerrero, M.W. Ellis, Journal of Power Sources, 218 (2012) 221-232.

[59] G. Luo, Y. Ji, C.-Y. Wang, P.K. Sinha, Electrochimica Acta, 55 (2010) 5332-5341. 